\title{
UNIVERSITYOF
}

FORWARD

THINKING

WESTMINSTER用

WestminsterResearch

http://www.westminster.ac.uk/westminsterresearch

\section{Trains, Twitter and the social license to operate: A case study analysis of Twitter use by train operating companies in the United Kingdom}

Howard, J. M.

NOTICE: this is the authors' version of a work that was accepted for publication in Case Studies on Transport Policy. Changes resulting from the publishing process, such as peer review, editing, corrections, structural formatting, and other quality control mechanisms may not be reflected in this document. Changes may have been made to this work since it was submitted for publication. A definitive version was subsequently published in Case Studies on Transport Policy,.

The final definitive version in Case Studies on Transport Policy is available online at:

https://dx.doi.org/10.1016/j.cstp.2020.06.002

(c) 2020. This manuscript version is made available under the CC-BY-NC-ND 4.0 license https://creativecommons.org/licenses/by-nc-nd/4.0/

The WestminsterResearch online digital archive at the University of Westminster aims to make the research output of the University available to a wider audience. Copyright and Moral Rights remain with the authors and/or copyright owners. 
1 Trains, Twitter and the social license to operate: A case study analysis of Twitter use by

2 train operating companies in the United Kingdom

3

\section{Abstract}

6 Social media has become a platform for passenger train operating companies to share 7 information and engage with their customers. Twitter, in particular, is used by operators to 8 provide live service updates and engage with their customers. A gap in the literature exists 9 regarding the concept of the social license to operate, where organisations engage with 10 stakeholders to gain legitimacy of their operations, within the transportation industry. Further, 11 there is a lack of literature on the use of social media by private train operating companies.

12 This article fills a gap in the literature regarding the use of Twitter by private passenger train 13 operating companies and use of this social media platform for obtaining a social license to 14 operate from customers. Therefore, the aim of this research is to understand how the functions 15 of Twitter use by private train operating companies in the United Kingdom can serve as a means to obtain a social license to operate through an analysis of their Twitter accounts, tweets, and policies. The findings indicate 1) that Twitter is primarily a tool for communication and engagement with their customers; 2) as Twitter functions evolved, providing customer service has become a key function; and 3) the key elements of the social license to operate: legitimacy, credibility, and trust; can be obtained through customer engagement using Twitter.

\section{Keywords}

23 Social Media; Twitter; Rail Transport; Transport Planning; Social License to Operate; 24 Customer Engagement 


\section{Introduction}

Social media, defined as internet applications where "individuals and communities share, create, discuss, and modify user-generated content" (Kietzmann et al., 2011, p. 241), has become an important part of a company's organisation (Meijer and Thaens, 2010). The use of internet technologies can aid in organisational and policy transparency, organisational and policy sector interactions, and the creation of innovative policies and processes. The use of social media is a means to establish trust and build a reputation (Kietzmann et al., 2011).

This is also true for companies operating in the transport field, where social media can serve as a tool for transport operators to engage with stakeholders. In the last decade, this specific topic is attracting attention of academia as researchers analysed the uses of social media in public transport, such as Bregman's (2012) report on social media practices of public transport operators; and how information received from social media users can be extracted and analysed for use in transport planning (Gal-Tzur et al., 2014; Grant-Muller et al., 2015; Kuflik et al., 2017).

In some contexts, the use of social media by public transport operators is wider, particularly in the United Kingdom who has pioneered privatisation of railway systems. Privatisation of the U.K.'s rail network has provided investors and companies with a far more open and competitive market than other European counterparts. More specifically, the rail system in the U.K. is comprised of four main actors: private train operating companies (TOC) and the government agencies of Network Rail, Department for Transport, and Office of Rail and Road. Funding and management of infrastructure is the responsibility of the government, who awards franchises and licenses and grants TOC access to infrastructure to provide passenger rail services (Abrams, 2015). Without the need to incorporate infrastructure in their planning, private TOCs are able to focus on serving the needs of customers and are responsible for operating train services, creating timetables, setting unregulated fares, determining service levels, and operating most stations (Abrams, 2015).

With the privatisation of rail services in the U.K., it becomes increasingly important for TOCs to gain or maintain legitimacy from their customers. The concept of the "social license to operate" (SLO) occurs when organisations engage their stakeholders to explain or justify its 
from their stakeholders (Demuijck and Fasterling, 2016). Whilst TOCs are subject to licensing

60 and regulations from the government, the SLO allows them to gain legitimacy of their activities from their stakeholders. Although stakeholders are a wide range of individuals, groups, and businesses affected by policies and activities of a company, this study focuses on only one of the TOC's stakeholder groups: their customers.

Despite the range of literature on the use of social media by transport operators, a gap exists when examining social media and customer engagement within the context of private passenger TOCs. Further, an examination of the SLO has not been examined in the context of public transport operators nor in the use of social media platforms. In the U.K. context, there is limited literature on passenger TOC's use of Twitter despite it being the only social media platform used by all TOCs in the U.K. One exception, however, is a study by Nisar and Prabhakar (2018) on the framing of messages by British TOCs in the context of consumer relationship management. A Passenger Focus (2012) study of social media use in England highlights the value of Twitter use by TOCs as it indicated that passengers prefer Twitter as the social media platform to receive information from rail operators.

This article contributes to existing literature by moving beyond basic social media use of public transport operators by examining Twitter as a means to obtain a social license to operate by private passenger rail operators. In order to address the gap in the research, study cases of the Twitter accounts, tweets, and policies of all private passenger TOCs in the U.K. were reviewed to understand the functions and extent to which they use Twitter. Using this analysis, the ways in which Twitter may be used as a tool to obtain a social license to operate was examined.

This article is presented in the following four sections. Section 2 presents a literature review. Section 3 provides the research methodology. The results are presented in Section 4, providing a critical analysis of the Twitter accounts of all private passenger rail operators in the U.K. Section 5 offers a conclusion of the research.

\section{Literature review}

2.1 Social license to operate (SLO) 
92 The SLO occurs when companies consult stakeholders to explain or justify an organisation's 93 activities, come to an agreement, and obtain the "license" to operate from their stakeholder 94 (Demuijnck and Fasterling, 2016). The SLO is not permanent, however, and is in a state of continual evaluation by stakeholders (Joyce and Thomson, 2000). Despite the legal right to operate, opposition from the community or other stakeholders can have a negative effect on an organisation's operations (Boutilier and Zdziarski, 2017). As a result, the SLO is verified through stakeholder actions to allow companies to continue operating.

Thomson and Boutilier (2011) further break the SLO into three key pieces: legitimacy, credibility, and trust. Legitimacy is considered to be the minimum requirement for a basic SLO, and that organisations must earn credibility and complete trust from stakeholders to achieve higher levels of a SLO (Thomson and Boutilier, 2011). The first of these key pieces, legitimacy, can be gained through communication of an organisation's activities and engagement with stakeholders (Thomson and Boutilier, 2011). Legitimacy can be explained from a normative perspective as having general approval for the practices of the organisation due to all groups being properly informed of an organisation's activities and the rational for those activities (Demuijnck and Fasterling, 2016). From an empirical approach, an organisation can also be perceived as being legitimate to conforming to social norms despite an understanding of the actual actions of the organisation (Demuijnck and Fasterling, 2016). Credibility occurs when organisations demonstrate openness and transparency in providing information and in their decision making (Thomson and Boutilier, 2011). Further, organisations must also keep their promises and be honest about their activities in order to earn and maintain credibility (Thomson and Boutilier, 2011). Finally, trust must be established between organisations, communities and governments in order for a SLO to be earned (Warhurst, 2001). In order to earn trust, organisations much earn a reputation for credibility (Thomson and Boutilier, 2011). Indeed,

117 reputation can be affected by how organisations are perceived by their communities 118 (Gunningham, Kagan, and Thornton, 2004; Joyce and Thomson, 2000).

Criticisms of the SLO relate to the varying interpretations of it, as discussed in a review of SLO literature by Brueckner and Eabrasu (2018). One criticism of the SLO is the lack of a clear definition and scope (Brueckner and Eabrasu, 2018). Questions arise on if the SLO applies to specific actions of an organisation or an entire organisation and all its operations (Brueckner and Eabrasu, 2018). There are also problems defining the stakeholders, with a range from local stakeholders to broader society (Brueckner and Eabrasu, 2018). Despite the lack of a clear 
126 definition of SLO, there is an agreement in the literature that SLO represents the relationship between an organisation and its stakeholders (Brueckner and Eabrasu, 2018).

129 The overall discussion on SLO suggests that the three key components of legitimacy, 130 credibility, and trust, are central for SLO analysis. Each of these requires an examination of 131 the stakeholder, which are customers for U.K. TOCs, and how companies engage with them in 132 obtaining the SLO. Indeed, the engagement with stakeholders and building relationships with 133 them is crucial to the obtaining the three key components and ultimately earning the social 134 license to operate. As TOCs in the U.K. are granted operational licenses by the government to operate, there is the risk of losing this license due to stakeholder resistance. As such, obtaining the SLO is important in legitimising their operations and avoiding resistance to their operations.

2.2 Main functions of Twitter use in transport

140 Literature on social media has shown that it has become a public engagement tool for transport operators, used to promote their services and solicit customer feedback (Manetti et al., 2016). The use of social media can be used as a means to establish trust and build a reputation

143 (Kietzmann et al., 2011). Social media is seen as a bottom-up platform where information is 144 voluntarily contributed by the public and can help transport agencies determine the needs of its users, allowing customers and operators to communicate directly with one another (Gal-Tzur et al., 2014). Twitter strongly favours these conversations with the exchange of information between users (Kietzmann et al., 2011). The use of social media as a tool for engaging customers in informal ways is one reason transport providers are adopting these applications to open up a new channel of engagement with their customers (Bregman, 2012). Reaching those who are more difficult or who are unwilling to reach out via conventional methods is also possible with social media, giving transport operators an additional engagement tool (Gal-Tzur et al., 2014; Grant-Muller et al., 2015). A study by Manetti et al. (2016) indicated that whilst both Facebook and Twitter are used for customer engagement, Facebook is more likely to be used to purposely engage with customers, whilst Twitter focuses on messages that share public information (Manetti et al., 2016).

Literature on transport use of Twitter, and social media in general, has focused on the uses and benefits. The widely cited Transit Cooperative Research Program (TCRP) study of American and Canadian transport agencies determined five main functions of social media: providing 
160

timely updates, sharing public information, public engagement, employee recognition, and entertainment (Bregman, 2012). Using social media to understand public sentiment has also been a focus of literature through the content analysis of public transport user's posts (Casas and Delmelle, 2017; Schweitzer, 2014; Collins, Hasan and Ukkusuri, 2013). Transport agencies benefit from social media through real-time data collection directly from users at minimal costs, giving agencies the ability to determine needs of specific users, and offering insight into riders' sentiments (Collins, Hasan and Ukkusuri, 2013; Gal-Tzur et al., 2014). Collecting data directly from users is beneficial as it can be a quick source of data that can be used until big data is made available (Rashidi et al., 2017). Information shared can be used in the development and implementation of user-led transport services (Gal-Tzur et al., 2014).

A common theme in the literature is the use of Twitter in sharing information. Twitter is the social media platform that is most often used for users to receive updated, current information from transport providers (Mellon and Prosser, 2017; Pender et al., 2014). The sharing of information in a timely manner is especially important for passenger railways, as they operate high-capacity networks that are reliant on technology where failures result in major service disruptions (Pender et al., 2014). A study by Gault et al. (2019) found that customers responded favourably to automated systems in social media that created a dialogue allowing them to message a transport operator to both receive travel information as well as to report service disruptions, creating a system beneficial to both operators and their customers. The ability of users of Twitter to share information in real-time, particularly during service disruptions and other incidents, is an important tool for transport agencies in managing their networks more efficiently and with a holistic view of situations (Rashidi et al., 2017). A study of Chiltern Railway's response to system disruptions indicated that in order to provide acceptable customer service levels, speed and accuracy of information was critical for effective response and recovery (Clegg et al., 2018).

Several barriers face transport operators when using social media, including allocation of resources to provide and maintain accounts, records retention requirements, security and privacy concerns, staff training, managing criticisms, and development and implementation of social media policies (Bregman, 2012; Manetti et al., 2016). The lack of understanding of the use of technology by staff can also serve as a barrier (Majumdar, 2017; Slotterback, 2011). Questions also remain on if technology can be successfully used as a participation tool (Slotterback, 2011). The provision of resources to implement and maintain technologies is also 
raised, as these might not be available (Bregman, 2012; Gal-Tzur et al., 2014; Majumdar, 2017;

195 Slotterback, 2011). In an increasingly digital world, transport agencies should embrace modern

196 technology or risk losing useful data. These criticisms, however, may be alleviated through the

197 investment in proper resources and training.

199 Literature on social media also raises criticisms that these applications do not reflect the general population, favouring a younger, more affluent and educated population (Collins, Hasan and Ukkusuri, 2013; Efthymiou and Antoniou, 2012; Schweitzer, 2014; Slotterback, 2011). A study of demographics of social media users in the U.K., included as part of the 2015 British Election Study, reflects the findings of the literature and indicates that social media users were not reflective of the overall British population, particularly in age and level of education, with users being younger and more educated than the overall population (Mellon and Prosser, 2017). Populations with lower income are often underrepresented as they may not be able to afford technology or resources to use social media applications (Collins, Hasan and Ukkusuri, 2013; Slotterback, 2011). Slotterback (2011) indicated that people with lower incomes, those less highly educated, and racial minorities are the least likely to participate in traditional engagement methods; and internet-based engagement may create a further disadvantage against participation by these communities. For transport operators in the U.K., this presents a

212 potential disadvantage in the use of Twitter as the social media platform does not reach all current and potential customers. Despite this, transport operators can use Twitter as an additional tool for engagement with customers.

\section{Methodology}

\subsection{Research framework}

The research framework (Figure 1) was adapted from the theories of Bregman's (2012) functional uses of social media by transport operators and of the social license to operate (Thomson and Boutilier, 2011). In order to assess the content of TOC Twitter activity, the functions from the TCRP study of social media were used (Table 1) to understand how TOCs use their Twitter accounts through a thematic analysis of their Twitter tweets and retweets (Bregman, 2012). The TCRP functions of social media, widely cited in the literature, were chosen for the analysis as they are a tested and proven means to analyse social media within the transport context. The analysis of Twitter use by TOCs was conducted in the context of 
obtaining the SLO through the three stages: legitimacy, credibility, and trust (Table 1). Customer engagement and communication are where the three SLO components and Twitter

230 come together. As communication and consultation with stakeholders are key to obtaining the 231 SLO (Thomson and Boutilier, 2011) and Bregman (2012) has identified the functions of social 232 media as a tool for transport agencies to engage with customers, Twitter use by TOCs was 233 examined in order to understand if it can be used as a tool for this purpose. A further analysis 234 of TOC Twitter policies was conducted in order to determine key themes. Once the key themes 235 of Twitter policies and functional analysis of Twitter accounts had been completed, these policies and functions were examined in the context of the key SLO components.

Figure 1: Research framework

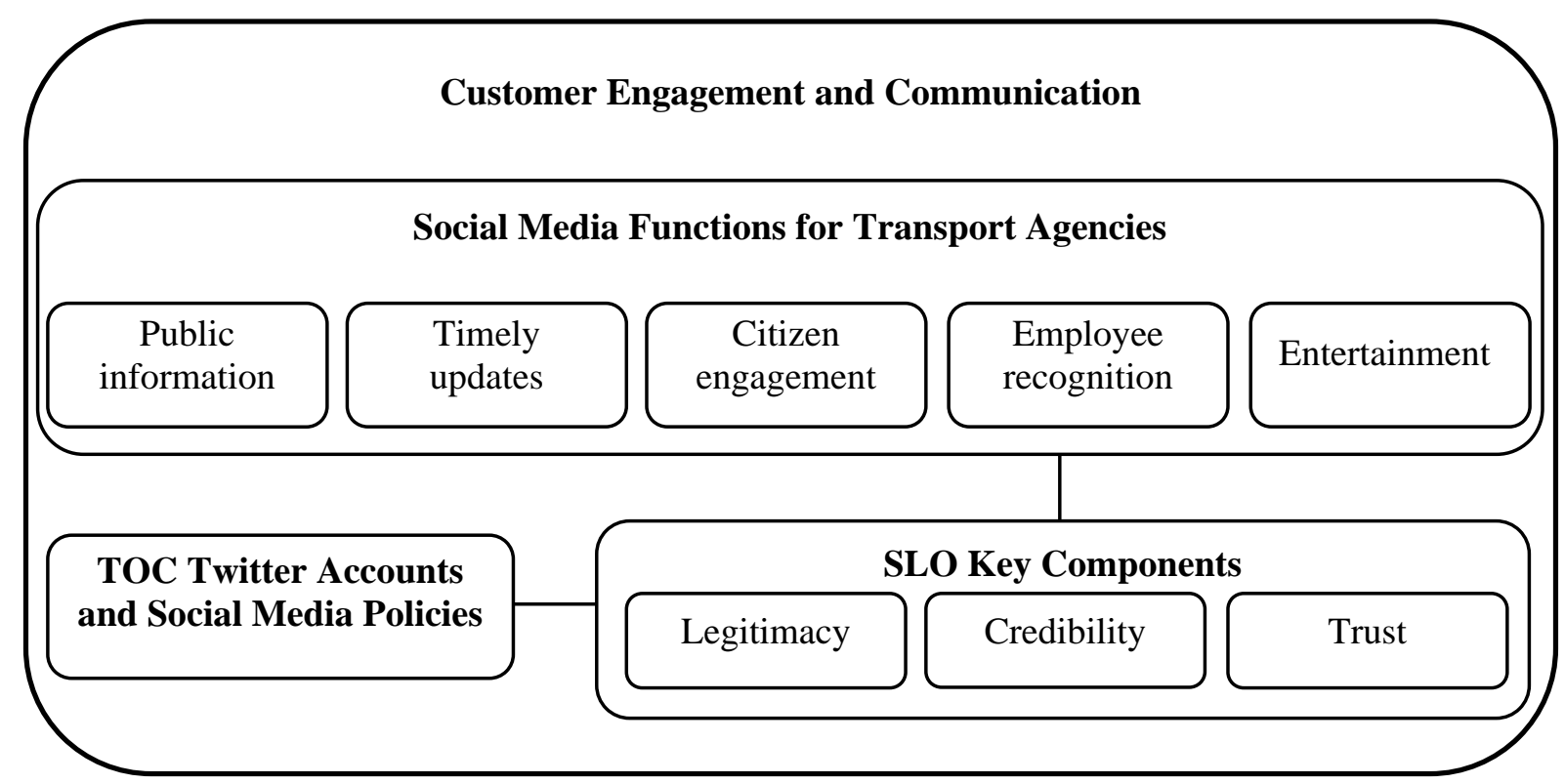

Developed by author, drawing from Bregman (2012) and Thomson and Boutilier (2011)

243 Three components of Twitter are used in the analysis: twitter activity consisting of tweets, 244 retweets, replies, and mentions; Twitter accounts consisting of the followers ratio of number 245 of followers to number of accounts followed, liked posts by customers, and shared posts by customers; and TOC social media policies. Analysing the content of the Twitter accounts, activity, and policies of TOCs was used to understand to what extent, if any, they are reflecting the components needed to earn a SLO. These components were examined, more specifically, as a means for TOCs to gain legitimacy for their operations. As legitimacy is required to gain credibility and trust (Thomson and Boutilier), the analysis also considers the role of Twitter

251 along within the process of

252 obtaining the SLO. 


\begin{tabular}{|c|c|}
\hline Social Media Function & Social Media Function Definition \\
\hline Timely updates & - Real-time information and service advisories \\
\hline Public information & - General information about services and schemes \\
\hline Citizen engagement & - Informal interaction with stakeholders and customers \\
\hline Employee recognition & - Employee recognition and recruitment \\
\hline Entertainment & $\begin{array}{l}\text { - Songs, videos, contests and other functions used to entertain riders } \\
\text { and personalise transport operators }\end{array}$ \\
\hline Miscellaneous & - Functions that do not fit the five categories above \\
\hline SLO Key Component & SLO Key Component Description \\
\hline Legitimacy & $\begin{array}{l}\text { - } \text { Gained through communication of activities and } \\
\text { engagement with stakeholders } \\
\text { - } \quad \text { Legitimacy can be gained by listening to stakeholders }\end{array}$ \\
\hline Credibility & $\begin{array}{l}\text { - Gained through demonstrating openness and transparency in } \\
\text { providing information and decision making } \\
\text { - Companies must be reliable, honest, and keep promises } \\
\text { - Reliability is earned through listening to stakeholders and responding } \\
\text { to their feedback }\end{array}$ \\
\hline Trust & $\begin{array}{l}\text { - Honesty and reliability are the basic level of trust } \\
\text { - Full trust is created when the community believes companies are } \\
\text { operating in the community's best interests }\end{array}$ \\
\hline
\end{tabular}

All TOCs, with the exception of the publicly operated Northern Ireland Railways, in the U.K. were included in the case study, consisting of private franchise, open access, and concession operators. The Campaign for Better Transport and Department for Transport Rail Executive (Abrams, 2015) explains the differences in private TOCs as (i) franchises where TOCs operate a rail service under contract and license from the government; (ii) open access operators who operate their own rail services and are regulated by the Office of Rail and Road; and (iii) concessions where services are contracted to private operators and managed by local transport authorities (Abrams, 2015). Including these three types of operators allowed for a complete analysis of all private TOCs in the U.K. 
271 Twitter data, which consists of TOC followers, accounts followed, tweets, retweets, replies, mentions, likes, and shares, used in the case study analysis was collected from TOC websites, and Twitter accounts. The TOC's Twitter pages provided information on the number of followers, number of accounts followed, tweets, retweets, and replies by the TOC. This data was analysed to determine tweet reach, levels of activity on Twitter, and levels of customer engagement through Twitter. Twitter activity was downloaded for each TOC on 6 August 2019 and included 3,200 of the most recent tweets, retweets, replies, and mentions created by TOCs; and likes and shares of TOC posts from Twitter users. The Twitter crawler Vicinitas, which uses the Twitter API download Twitter activity into spreadsheets, was used to capture and download the Twitter activity for each TOC. In order to verify accuracy of the data, every 100 tweets from each TOC account was reviewed on their individual Twitter pages, which resulted in not inaccuracies. Due to limitations set by Twitter, the maximum amount of Twitter account data that could be downloaded was limited to 3,200 tweets, etc.

The Twitter data of all TOCs was analysed for the week of 29 July 2019 (Monday through Sunday). This week was chosen as it is representative of Twitter data for TOCs. Specifically, this week was chosen as it was a standard working week with no bank holidays or was set during a larger holiday period, such as the Christmas period which includes increased trips due to shopping and other activities. Further, a week in summer with both normal temperatures as well as high temperatures was chosen to represent both settled weather and weather-related challenges of the effects of high temperatures, which represent poor weather conditions faced by TOCs throughout the year. One exception to this timeframe is Northern, which reached the limit of 3200 tweets after 29 July. As such, Northern's data was analysed for 31 July through 5 August 2019 (Wednesday through Monday). For operators that had a combination of tweets, retweets, and replies of less than 200 during the week of 29 July, the entire month of July 2019 was analysed to increase those sample sizes for the content analysis. Separate data on the followers and accounts followed was captured on 12 November 2019. This data fluctuates on a daily basis and Twitter activity is not a requirement for this activity to take place. As such, followers and accounts followed are a separate analysis from Twitter activity, allowing for the most recent data to be captured. 
302 The tweets and retweets were analysed based on the five categories (Table 2) indicated in the 303 TCRP study (Bregman, 2012): "Real-time Information", "Public Information", “Citizen 304 Engagement", "Employee Recognition”, and "Entertainment". One additional category, "Miscellaneous", was included for tweets that do not fall within the TCRP categories. The tweet and retweet content were analysed and hand coded (into these six categories by an individual researcher. Hand coding was choses and it is considered to produce the highest quality of tweet analysis (Murthy, 2017). The definitions from each category (Table 1) were used in the categorisation. Tweets were analysed for their content twice and categorised; the initial categorisation and a second categorisation were conducted independent of one another in order to note any discrepancies the analysis. A comparison of the two tweet/retweet categorisations was conducted to determine any discrepancies. Where discrepancies occurred, the content was compared to similar tweets and retweets and their categorisation to ensure the same definition of each category was applied in the content analysis. In some instances, multiple categories were applied to tweets and retweets, e.g. a single tweet being categorised as both "Public Information" and "Entertainment". Whilst user tweets are not available in the data set, the content of replies to user Tweets were also analysed to understand types of interactions and functions being performed by the TOCs. Finally, he examination of TOC Twitter account followers, accounts followed, follower ratio, mentions, and likes and shares of TOC posts by customers seeks to serve as a measurement of engagement with customers. The follower ratio was calculated as the number of followers a TOC Twitter account has for every account it follows.

324 TOC Twitter policies were analysed to determine key policy areas. Policies from 18 TOCs were analysed from publicly available policies on their websites as of 9 September 2019. TOC policies analysed include: c2c (2019), Cross Country (2019), Grand Central (2018), Greater Anglia (2019), Great Northern (2019), Hull Trains (2016), London Northwestern Railway (2019), Merseyrail (2019), Northern (2019), ScotRail (2019), South Western Railway (2019), Southeastern (2019), Southern Railway (2019), Thameslink (2019), TransPennine Express

330 (2019), Transport for London (2019), Transport for Wales Rail (2019) and West Midlands

331 Railway (2019). Using the tweet categorisation and key policy themes, an analysis was conducted to determine if and how the social license to operate was reflected. It should be noted that the categorisation of tweets and key policy areas is subjective and will vary from person to person based on how the tweets are interpreted. In response to the subjective nature 
of categorisation of tweets, the inclusion of a TOC Twitter policy analysis provides a means of

336 analysing Twitter functions.

\section{Results}

\subsection{Train operating companies' Twitter activity analysis}

342 Engaging with customers was examined through several measurements of interaction with

343 followers (Table 2). Whilst the number of followers an account indicates the potential direct 344 reach of each tweet, interactions between TOCs and Twitter users suggest a level of 345 engagement through responding to mentions of the TOC by users, indicating TOCs are 346 proactively reading the tweets of others. Mentions from TOCs also provide an indicator that 347 they are engaging with Twitter users by directly mentioning them in their tweets. Similarly,

348 the number of replies to tweets gives an indication of two-way communication between the rail operator and users. These replies and mentions are closely tied together and in these cases are similar in numbers, as replies will include a mention of the original tweet's writer. Further, when considering the number of followers each TOC has on Twitter, the number of replies to customers indicates that a small proportion of those followers are engaging with the TOC. The news accounts for TOCs, however, showed very little customer engagement through replies, with the exception of South Western Railway which only posted one Tweet but replied to 195 tweets of users.

Table 2: Train operating company Twitter account interactions:

Week of 29 July 2019.

All figures are actual numbers.

Source: Twitter

\begin{tabular}{|c|c|c|c|c|c|c|}
\hline $\begin{array}{c}\text { Train Operating Company } \\
\text { Twitter Account }\end{array}$ & Tweets & Retweets & Replies & Mentions & Likes & Shares \\
\hline & \multicolumn{4}{|c|}{ Train Operating Company Interactions } & \multicolumn{2}{|c|}{$\begin{array}{l}\text { Customer } \\
\text { Response }\end{array}$} \\
\hline \multicolumn{7}{|c|}{ Open Access Operators } \\
\hline Grand Central & 19 & 0 & 213 & 236 & 65 & 16 \\
\hline Heathrow Express & 33 & 0 & 45 & 51 & 19 & 8 \\
\hline Hull Trains & 51 & 0 & 335 & 353 & 325 & 231 \\
\hline \multicolumn{7}{|c|}{ Concession Operators } \\
\hline London Overground & 29 & 8 & 63 & 96 & 131 & 142 \\
\hline Merseyrail & 122 & 7 & 109 & 153 & 317 & 283 \\
\hline Transport for London Rail & 34 & 0 & 69 & 88 & 49 & 20 \\
\hline
\end{tabular}




\begin{tabular}{|c|c|c|c|c|c|c|}
\hline c2c Rail & 39 & 2 & 411 & 444 & 126 & 41 \\
\hline Caledonian Sleeper & 8 & 0 & 20 & 23 & 77 & 31 \\
\hline Chiltern Railways & 57 & 2 & 262 & 336 & 91 & 66 \\
\hline CrossCountry & 27 & 2 & 904 & 1,042 & 257 & 192 \\
\hline East Midlands Railway & 14 & 9 & 450 & 496 & 204 & 196 \\
\hline Gatwick Express & 8 & 2 & 39 & 54 & 28 & 19 \\
\hline Great Northern & 25 & 0 & 490 & 517 & 122 & 92 \\
\hline Great Western Railway & 3 & 9 & 1,481 & 1,679 & 605 & 175 \\
\hline London North Eastern Railway & 68 & 60 & 1,774 & 2,094 & 3,482 & 1,852 \\
\hline ScotRail & 163 & 55 & 1,527 & 2,010 & 3,868 & 1,709 \\
\hline Southeastern & 86 & 5 & 1,398 & 1,664 & 300 & 187 \\
\hline Southern & 46 & 17 & 705 & 904 & 409 & 389 \\
\hline Stansted Express & 182 & 0 & 55 & 55 & 43 & 1 \\
\hline Thameslink & 38 & 10 & 746 & 858 & 318 & 256 \\
\hline Transport for Wales Rail & 59 & 10 & 772 & 1,044 & 278 & 206 \\
\hline Virgin Trains & 7 & 0 & 2,120 & 2,572 & 902 & 89 \\
\hline \multicolumn{7}{|c|}{ Franchise Operator: Multiple Twitter Accounts } \\
\hline Greater Anglia News & 15 & 33 & 16 & 85 & 531 & 507 \\
\hline Greater Anglia (Help) & 552 & 7 & 1,125 & 1,206 & 644 & 285 \\
\hline London Northwestern Railway News & 1 & 2 & 0 & 3 & 3 & 13 \\
\hline London Northwestern Railway (Help) & 22 & 5 & 280 & 303 & 66 & 22 \\
\hline Northern News & 1 & 5 & 1 & 2 & 2 & 14 \\
\hline Northern (Help) & 258 & 40 & 2,263 & 2,644 & 851 & 967 \\
\hline TransPennine Express (News) & 5 & 2 & 0 & 2 & 113 & 20 \\
\hline TransPennine Express (Help) & 44 & 13 & 597 & 721 & 212 & 203 \\
\hline South Western Railway (News) & 1 & 0 & 195 & 274 & 39 & 13 \\
\hline South Western Railway (Help) & 69 & 0 & 1,116 & 1,401 & 273 & 141 \\
\hline West Midlands Railway News & 3 & 4 & 0 & 14 & 8 & 30 \\
\hline West Midlands Railway (Help) & 25 & 3 & 271 & 299 & 113 & 59 \\
\hline
\end{tabular}

361 TOC Twitter functions primarily consist of tweets and retweets, when excluding the

362 "Miscellaneous" function, for the sharing of information through "Timely Updates" and

363 "Public Information". Table 3 offers an overview of the number of tweets in each functional

364 category. In all but four of the rail operator's accounts examined, the sharing of real-time

365 information plays the primary role for these accounts. The franchise news accounts were less

366 likely, however, to share timely updates. As the majority of TOCs use one Twitter account, the

367 tweets and retweets of TOCs with separate accounts were combined in the analysis of these

368 functions. Variability in the "Timely Updates" category should be noted, as updates are largely

369 based on service disruptions. During disruptions, the number of timely updates would increase

370 to reflect this. Given this fluctuation, it is helpful to look at both "Timely Updates" and "Public

371 Information" together. Looking at "Public Information" separately, this would represent the

372 largest number of tweets across the remaining functions in all but eight of the TOCs. Overall,

373 "Citizen Engagement" was the third highest use of Twitter for TOCs. 
375 In comparing the types of rail operators, there were a few differences in the functions of 376 Twitter. Open access operators differed from other operators as 'Citizen Engagement' was 377 their second highest function. Concession and open access operators differed from franchises 378 with limited or no "Employee Recognition" and "Entertainment" tweets. These two categories, 379 however, do not contribute to obtaining a SLO as they are not focused on stakeholder 380 engagement. Despite not sharing timely updates, news accounts still reflect a means to obtain 381 the SLO, however, as public information and citizen engagement are their highest functions. 
Table 3: Tweet analysis of train operating companies: Week of 29 July 2019

Figures in italics indicates figures from the month of July 2019. Figures listed in parenthesis are actual numbers. Source: Twitter

\begin{tabular}{|c|c|c|c|c|c|c|c|}
\hline Train Operating Company & $\begin{array}{l}\text { Tweets \& } \\
\text { Retweets }\end{array}$ & $\begin{array}{c}\text { Timely } \\
\text { Updates }\end{array}$ & $\begin{array}{c}\text { Public } \\
\text { Information }\end{array}$ & $\begin{array}{c}\text { Citizen } \\
\text { Engagement }\end{array}$ & $\begin{array}{c}\text { Employee } \\
\text { Recognition }\end{array}$ & Entertainment & Miscellaneous \\
\hline Grand Central & 19 & $26.3 \%(5)$ & $\mathbf{5 . 3 \%}(1)$ & $\mathbf{4 2 . 1 \%}(8)$ & $\mathbf{0 . 0 \%}(0)$ & $\mathbf{0 . 0 \%}(0)$ & 68.4\% (13) \\
\hline Hull Trains & 51 & $\mathbf{9 0 . 2 \%}(46)$ & $\mathbf{3 . 9 \%}(2)$ & $\mathbf{5 . 9 \%}(3)$ & $\mathbf{2 . 0 \%}(1)$ & $\mathbf{0 . 0 \%}(0)$ & $\mathbf{2 . 0 \%}(1)$ \\
\hline \multicolumn{8}{|c|}{ Concession Operators } \\
\hline Merseyrail & 129 & $\mathbf{6 2 . 0 \%}(80)$ & $\mathbf{3 4 . 1 \%}(44)$ & $\mathbf{7 . 0 \%}(9)$ & $\mathbf{0 . 0 \%}(0)$ & $1.6 \%(2)$ & $10.9 \%(14)$ \\
\hline Transport for London Rail & $\begin{array}{c}34 \\
259\end{array}$ & $\begin{array}{l}\mathbf{1 0 0 . 0 \%}(34) \\
\mathbf{9 9 . 2 \%}(257)\end{array}$ & $\begin{array}{l}\mathbf{5 . 9 \%}(2) \\
\mathbf{0 . 0 \%}(0)\end{array}$ & $\begin{array}{l}\mathbf{0 . 0 \%}(0) \\
\mathbf{0 . 8 \%}(2)\end{array}$ & $\begin{array}{l}\mathbf{0 . 0 \%}(0) \\
\mathbf{0 . 0 \%}(0)\end{array}$ & $\begin{array}{l}\mathbf{0 . 0 \%}(0) \\
0.4 \%(1)\end{array}$ & $\begin{array}{l}\mathbf{2 9 . 4 \%}(10) \\
\mathbf{1 3 . 9 \%}(36)\end{array}$ \\
\hline \multicolumn{8}{|c|}{ Franchise Operators: Single Twitter Accounts } \\
\hline c2c Rail & 41 & $\mathbf{9 2 . 7 \% ( 3 8 )}$ & $\mathbf{4 . 6 \%}(2)$ & $17.1 \%(7)$ & $2.4 \%(1)$ & $\mathbf{0 . 0 \%}(0)$ & $17.1 \%(7)$ \\
\hline East Midlands Railway & 23 & $69.6 \%(16)$ & $1.5 \%(1)$ & $21.7 \%(5)$ & $4.3 \%(1)$ & $8.7 \%(2)$ & $4.3 \%(1)$ \\
\hline Gatwick Express & $\begin{array}{l}10 \\
51\end{array}$ & $\begin{array}{l}\mathbf{7 0 . 0 \%}(7) \\
82.4 \%(42)\end{array}$ & $\begin{array}{c}\mathbf{6 0 . 0 \%}(6) \\
\mathbf{2 7 . 5 \%}(14)\end{array}$ & $\begin{array}{c}\mathbf{3 0 . 0 \%}(3) \\
\mathbf{5 . 9 \%}(3)\end{array}$ & $\begin{array}{l}\mathbf{0 . 0 \%}(0) \\
\mathbf{3 . 9 \%}(2)\end{array}$ & $\begin{array}{l}10.0 \%(1) \\
13.7 \%(7)\end{array}$ & $\begin{array}{c}10.0 \%(1) \\
3.9 \%(2)\end{array}$ \\
\hline Great Northern & 25 & $84.0 \%(21)$ & $\mathbf{8 . 0 \%}(2)$ & $\mathbf{8 . 0 \%}(2)$ & $\mathbf{0 . 0 \%}(0)$ & $4.0 \%$ & $4.0 \%(1)$ \\
\hline Great Western Railway & 12 & $9.1 \%(1)$ & $18.2 \%(2)$ & $18.2 \%(2)$ & $\mathbf{0 . 0 \%}(0)$ & $45.5 \%(5)$ & $45.5 \%(5)$ \\
\hline London North Eastern Railway & 128 & $41.4 \%(53)$ & $\mathbf{5 7 . 0 \%}(73)$ & $49.2 \%(63)$ & $4.7 \%(6)$ & $18.0 \%(23)$ & $4.7 \%(6)$ \\
\hline ScotRail & 218 & $\mathbf{3 8 . 1 \%}(83)$ & $55.5 \%(121)$ & $21.6 \%(47)$ & $0.9 \%(2)$ & $25.2 \%(55)$ & $10.1 \%(22)$ \\
\hline
\end{tabular}




\begin{tabular}{|c|c|c|c|c|c|c|c|}
\hline Southeastern & 85 & $\mathbf{9 8 . 8 \%}(84)$ & $20.0 \%(17)$ & $1.2 \%(1)$ & $\mathbf{0 . 0 \%}(0)$ & $\mathbf{2 . 4 \%}(2)$ & $\mathbf{0 . 0 \%}(0)$ \\
\hline Southern & 62 & $\mathbf{8 0 . 6 \%}(50)$ & $62.9 \%(39)$ & $24.2 \%(15)$ & $4.8 \%(3)$ & $16.1 \%(10)$ & $\mathbf{0 . 0 \%}(0)$ \\
\hline Thameslink & 48 & $\mathbf{8 1 . 3 \%}(39)$ & $\mathbf{5 0 . 0 \%}(24)$ & $18.8 \%(9)$ & $\mathbf{0 . 0 \%}(0)$ & $12.5 \%(6)$ & $\mathbf{2 . 1 \%}(1)$ \\
\hline Virgin Trains & 6 & $\mathbf{2 8 . 6 \%}(2)$ & $\mathbf{0 . 0 \%}(0)$ & $\mathbf{2 8 . 6 \%}(2)$ & $14.3 \%(1)$ & $57.1 \%(4)$ & $\mathbf{0 . 0 \%}(0)$ \\
\hline \multicolumn{8}{|c|}{ Franchise Operators: Multiple Twitter Accounts } \\
\hline Greater Anglia News & $\begin{array}{c}48 \\
213\end{array}$ & $\begin{array}{c}\mathbf{0 . 0 \%}(0) \\
12.7 \%(27)\end{array}$ & $\begin{array}{l}\mathbf{1 0 0 . 0 \%}(48) \\
\mathbf{9 3 . 0 \%}(198)\end{array}$ & $\begin{array}{l}\mathbf{7 0 . 8 \%}(34) \\
\mathbf{4 2 . 7 \%}(91)\end{array}$ & $\begin{array}{l}\mathbf{2 . 1 \%}(1) \\
7.0 \%(15)\end{array}$ & $\begin{array}{l}22.9 \%(11) \\
27.7 \%(59)\end{array}$ & $\begin{array}{l}0.0 \%(0) \\
1.4 \%(3)\end{array}$ \\
\hline London Northwestern Railway News & $\begin{array}{c}3 \\
30\end{array}$ & $\begin{array}{c}\mathbf{0 . 0 \%}(0) \\
26.7 \%(8)\end{array}$ & $\begin{array}{l}100.0 \% \\
76.7 \%\end{array}$ & $\begin{array}{l}\mathbf{1 0 0 . 0 \%}(3) \\
\mathbf{5 3 . 3 \%}(16)\end{array}$ & $\begin{array}{l}66.7 \%(2) \\
20.0 \%(6)\end{array}$ & $\begin{array}{l}0.0 \%(0) \\
10.0 \%(3)\end{array}$ & $\begin{array}{l}\mathbf{0 . 0 \%}(0) \\
\mathbf{0 . 0 \%}(0)\end{array}$ \\
\hline London Northwestern Railway (Help) & 23 & $\mathbf{7 8 . 3 \%}(18)$ & $17.4 \%(4)$ & $21.7 \%(5)$ & $21.7 \%(5)$ & $4.3 \%(1)$ & $\mathbf{0 . 0 \%}(0)$ \\
\hline Northern News & $\begin{array}{c}6 \\
11\end{array}$ & $\begin{array}{l}16.7 \% \\
16.7 \%\end{array}$ & $\begin{array}{l}\mathbf{8 3 . 3 \%}(5) \\
\mathbf{8 3 . 3 \%}(5)\end{array}$ & $\begin{array}{l}\mathbf{0 . 0 \%}(0) \\
\mathbf{0 . 0 \%}(0)\end{array}$ & $\begin{array}{l}16.7 \% \\
16.7 \%(1)\end{array}$ & $\begin{array}{l}\mathbf{8 3 . 3 \%}(5) \\
83.3 \%(5)\end{array}$ & $\begin{array}{l}\mathbf{0 . 0 \%}(0) \\
\mathbf{0 . 0 \%}(0)\end{array}$ \\
\hline TransPennine Express (News) & $\begin{array}{c}7 \\
45\end{array}$ & $\begin{array}{l}\mathbf{0 . 0 \%}(0) \\
\mathbf{4 . 4 \%}(2)\end{array}$ & $\begin{array}{l}\mathbf{8 5 . 7 \%}(6) \\
\mathbf{9 7 . 8 \%}(44)\end{array}$ & $\begin{array}{l}\mathbf{5 7 . 1 \%}(4) \\
\mathbf{4 6 . 7 \%}(21)\end{array}$ & $\begin{array}{l}14.3 \% \\
15.6 \%(7)\end{array}$ & $\begin{array}{c}\mathbf{5 7 . 1 \%}(4) \\
\mathbf{4 . 4 \%}(2)\end{array}$ & $\begin{array}{l}\mathbf{0 . 0 \%}(0) \\
\mathbf{0 . 0 \%}(0)\end{array}$ \\
\hline TransPennine Express (Help) & 47 & $95.7 \%(45)$ & $\mathbf{2 . 1 \%}(1)$ & $\mathbf{0 . 0 \%}(0)$ & $\mathbf{0 . 0 \%}(0)$ & $\mathbf{4 . 3 \%}(2)$ & $2.1 \%(1)$ \\
\hline West Midlands Railway News & $\begin{array}{c}9 \\
30\end{array}$ & $\begin{array}{l}14.3 \% \\
16.7 \%\end{array}$ & $\begin{array}{c}85.7 \%(6) \\
86.7 \%(26)\end{array}$ & $\begin{array}{l}\mathbf{5 7 . 1 \%}(4) \\
\mathbf{4 0 . 0 \%}(12)\end{array}$ & $\begin{array}{c}14.3 \%(1) \\
6.7 \%(2)\end{array}$ & $\begin{array}{l}\mathbf{0 . 0 \%}(0) \\
\mathbf{0 . 0 \%}(0)\end{array}$ & $\begin{array}{l}\mathbf{0 . 0 \%}(0) \\
\text { 0.0\%(0) }\end{array}$ \\
\hline West Midlands Railway (Help) & 22 & $86.4 \%(19)$ & $13.6 \%(3)$ & $18.2 \%(4)$ & $9.1 \%(2)$ & $\mathbf{0 . 0 \%}(0)$ & $\mathbf{0 . 0 \%}(0)$ \\
\hline
\end{tabular}


Analysing the tweets and retweets of the TOCs also provides an indication of the functions

387 Bregman's (2012) categories. Whilst nearly all tweets and retweets fit into one of these

388 functions, a number of them contained content that did not reflect the functions. In response to

389 this, an additional category, "Miscellaneous", was used to note these tweets. These

390 "Miscellaneous" tweets consisted of staff publicly signing in and out, as well as lost and found

391 items. Tweets and retweets also could be considered a part of multiple categories, which is

392 reflected in the analysis. Examples of tweets included in these categories are shown in Table

3934.

Table 4: Tweet function examples

Source: Twitter

\section{Timely Updates}

@CalSleeper (Caledonian Sleeper): 30 July 2019

London Euston to Glasgow/Edinburgh: Boarding will be delayed by approximately 30 minutes due to the train being late leaving Wembley depot. The train is on its way to London Euston now, and should depart London Euston on time. We apologise to guests for any inconvenience caused.

\section{Public Information}

@ Iner (London North Eastern Railway): 31 July 2019

Let's eat and avocuddle - it's officially \#NationalAvocadoDay [avocado emoji] Have you tried our delicious @HolyMolyDips breakfast avocado on sourdough muffin with fresh sliced tomato and a free range egg yet? You can check out our first class menu here: [link to first class menus website] [image of breakfast food]

\section{Citizen Engagement}

@ ScotRail (ScotRail): 29 July 2019

The votes are in! Our inter-city high-speed train's engine is going to be... *drumroll please* PINK! Thanks to everyone who voted, the engine will be fitted later in the year and we'll have plenty of pictures when it arrives! [link to original survey] [photo of pink train engine]

\section{Employee Recognition}

@GC_Rail (Grand Central): 1 July 2019

VACANCY: Roster Assistant We have an exciting opportunity to join our Rostering Department to help with the day to day operational running of our trains. With fantastic employee benefits including free train travel, this is the perfect time to join. Visit: [link to job application] [image of train with heading "Careers at Grand Central"]

\section{Entertainment}

@ northernassist (Northern): 5 August 2019

This week, ^LH has put together a game of \#SummerScrabble! Can you join on a summer-related word using some of the letters below? [finger pointing down emoji] HINT: You can swim here.

\section{Miscellaneous}


@ GWRHelp (Great Western Railway): 30 July 2019

A very important microwaveable soup container has been lost! [sad emoji] The very kind Ticket

Examiners at Hanborough will hold onto it for the week [thumbs up emoji] [picture of container]

4.2 Train operating companies' Twitter policies

The majority of TOCs in the U.K. publish their Twitter policies on their websites. These policies are often grouped with other social media policies, however the emphasis of these policies is Twitter. Within these Twitter policies, four main policy areas emerged: Twitter functions, customer engagement, customer etiquette, and responses to customers (Table 5). These policies offer a transparent guide for customers and may help manage their expectations regarding how TOCs use Twitter.

405

Table 5: Train operating companies' Twitter policy overview

\begin{tabular}{l|rl}
\hline Twitter policy area & Key points \\
\hline Twitter Functions & - & Differentiate Twitter functions from other social media \\
& - & Hours Twitter feed is monitored \\
\hline Customer Engagement & - & Types of information shared and services provided on Twitter \\
& - & Types of customer service functions provided \\
& - & Formal complaints not accepted via Twitter \\
\hline Customer Etiquette & - & Ways customers can engage in conversations \\
& - & Guidelines for respectful dialogue \\
\hline Responses to Customers & - & Response to abusive or inappropriate comments \\
& - What is done with feedback shared by customers \\
& - & Limited or no responses to customers during service disruptions \\
\hline
\end{tabular}

408 The policy area, "Twitter Functions", defines the use of the social media platform by the TOC.

409 This area describes the functional differences between Twitter and other social media platforms 410 such as Facebook, Instagram, or LinkedIn. For example, South Western Railway's (2019) 411 social media guide differentiates between the social media platform, as well as the managing 412 department for each. The policy area sets out the hours the account is staffed and monitored, 413 as well as the information shared, and services provided through Twitter. The importance of 
414 sharing information with customers is the prominent function of Twitter as indicated in 415 policies, whether that is through proactive tweets or responding to customer tweets and 416 messages. In clearly defining these functions, TOCs may be able to manage customer's 417 expectations and define the context in which they can engage with the TOC through Twitter.

\subsection{Legitimacy}

Legitimacy can be gained through engaging with and listening to stakeholders and communication of a company's activities (Thomson and Boutilier, 2011). When analysing the tweets and retweets of TOC, the most prominent categories of "Citizen Engagement" and the information sharing categories of "Timely Updates" and "Public Information" lend themselves to obtaining legitimacy. Engaging with customers is represented in the "Citizen Engagement", which is the second highest category of TOC-initiated tweets after information sharing. Stakeholder engagement was evident in the use of Twitter to inform customers of their functions, as seen through the sharing of public information such as service changes or the creation of separate Twitter news accounts that focus on the activities of TOCs. Whilst "Timely Updates" can share information on activities, "Public Information" tends to focus on the company's activities rather than service updates. Several TOCs have created separate news accounts, providing a dedicated space for communication of a TOC's activities.

An examination of Twitter accounts also suggests legitimacy is being earned through Twitter. The high number of customers sharing and liking TOC tweets suggests legitimate communication and engagement with customers. The low number of customers tweeting to TOCs in comparison to the large number of followers also suggests there is less opposition to the TOCs operations. There is little evidence in challenges to TOCs via Twitter, which may represent less pushback from customers, suggesting a constructive engagement between the TOC and their customers and gaining legitimacy of their operations by their customers.

442 Gaining legitimacy is also reflected in the TOC Twitter policies. The policy area, "Twitter 443 Functions", defines the use of the social media platform by the TOC. This area describes the 444 functional differences between Twitter and other social media platforms such as Facebook, 445 Instagram, or LinkedIn. For example, South Western Railway's (2019) social media guide 446 differentiates between the social media platform, as well as the managing department for each.

447 The policy area sets out the hours the account is staffed and monitored, as well as the 
information shared, and services provided through Twitter. The importance of sharing information with customers is the prominent function of Twitter as indicated in policies, whether that is through proactive tweets or responding to customer tweets and messages. In clearly defining these functions, TOCs may be able to manage customer's expectations and define the context in which they can engage with the TOC through Twitter. This policy area's focus on sharing information and customer engagement are the two main pieces necessary to gain legitimacy.

\subsection{Credibility}

Companies need to be reliable, honest, and demonstrate transparency in providing information and decision making in order to gain credibility (Thomson and Boutilier, 2011). This is especially evident in the "Timely Updates" category, , the sharing of real-time updates for service disruptions may reflect negatively on TOCs. TOC tweets, however, often disclose the cause of the delays. Also important is that this information is shared in a timely matter in order for customers to plan their journeys. Service delays run the risk for services being seen as unreliable, which may threaten the credibility of the TOCs. Despite the potential loss of reliability in providing services, there is opportunity to be seen as reliable through the consistent provision of updates in a timely manner. Further, acknowledging service delays and their causes can be seen as being transparent and honest about the causes, efforts to correct the delay, and accepting responsibility for the effects on customers.

The sharing of information in the "Public Information" category also provides TOCs an opportunity to share schemes and long-term plans to customers. This sharing of information can provide the openness and transparency, as well as to listen to stakeholders and respond to their feedback. Given the high volume "Timely Updates", it is possible for "Public Information" tweets to be lost in the large number of tweets. Whilst most of the TOCs use one

475 Twitter account to share information, a few TOCs separate news and assistance functions into two separate Twitter accounts. Providing separate accounts gives these TOCs the ability to share information without it getting overlooked in numerous real-time updates. The danger in this approach, however, is that having multiple accounts may confuse customers looking for information. Despite this, providing separate accounts can assist in providing transparency in

480 their activities. This openness and transparency assist in gaining credibility (Thomson and 481 Boutilier, 2011). 
483 The replies to other Twitter users give an indication of additional functions of Twitter. In 484 keeping with the sharing of information, many replies share real-time service information or assistance with journeys. TOCs will also respond to messages that are not enquiries that may include user tweets about their journeys. An additional function of customer service has also been observed in the replies. These customer service functions involve replies involving information on seat reservations or compensation for delayed services. As the nature of social media constantly evolves, a new category of "Customer Service", which was not included in 490 Bregman's (2012) study, may be incorporated to encompass past and current functions. 491 Further, miscellaneous functions reflect aspects of customer service and could be included in 492 that function to create a more wholistic view of social media functions and customer 493 engagement.Citizen engagement was reflected in all of the TOC Twitter accounts. This category reflected tweets that invited their followers to interact with them. This invitation could take the form of proactively asking customers to ask questions, providing customer surveys, by responding to tweets or retweeting, or other forms of inviting the public to engage with them or acknowledging the tweets of others. Whilst this category was analysed through the tweets and retweets of the Twitter accounts, any reply could be considered form of citizen engagement. Considering the aggregate of all of TOC tweets, retweets, and replies, citizen engagement would surpass all other Twitter functions. Similar engagement by customers would further add to this category as engagement is derived from both the TOC and customer. Whilst the sharing of information is prominent in the TOC tweets and retweets, it is the engagement with customers that forms the primary function of Twitter as observed through this Twitter data.

TOC Twitter policies reflect using it as a form of not only listening to feedback, but also responding to their customers. Twitter lends itself to social media's bottom-up approach to engagement (Gal-Tzur et al., 2014), and this is reflected in the Twitter "Customer Engagement" policy area. TOCs specifically focus on how Twitter is used as a customer service function, encouraging feedback from customers, and clarifying processes for formal complaints. The policies suggest that most of the engagement comes in the form of customer services, with 512 operators responding to enquiries on service information. Whilst formal complaints aren't 513 logged through Twitter, TOCs clarified that any feedback offered, positive or negative, would 514 be shared appropriately and acted upon. Despite the welcoming of feedback, the venting of customer frustrations, presence of sarcasm, and lack of context in customer tweets can present 
516 a challenge to TOCs and make analysing sentiment difficult. This may explain why TOCs

517 clearly state that formal complaints are not accepted via Twitter, as it is not always possible to

518 accurately assess the meaning behind these tweets. These rules suggest there is a desire for

519 TOCs to engage in a genuine, constructive dialogue with their customers.

520

521 Earning credibility is also reflected in the "Customer Etiquette" and "Responses to Customers"

522 policy areas. Customer etiquette, how TOCs expect customers to behave and engage on

523 Twitter, is related to customer engagement and receives specific attention in each TOC Twitter

524 policy. All TOCs refuse to respond to abusive comments and, in serious cases, will block accounts they deem excessively breaching this policy. TOC Twitter policies further clarify which enquiries they provide responses, as well as response times to customers. Further, each rail operator sets its own parameters for responding to questions through tweets and direct messages. These policies vary, however, from responding to each customer tweet and message, to answering questions that are most relevant or useful to other customers, or how TOCs respond to customers during disruptions. These policies demonstrate openness and transparency in providing information and communicating decisions on their use of Twitter, as well as indicating their commitment to responding to customers rather than simply listening to them. This is especially important as they are key pieces to gaining credibility (Thomson and Boutilier, 2011).

\subsection{Trust}

Trust is closely related to credibility as they both involve honesty and reliability, which form the basic level of trust (Thomson and Boutilier, 2011). Whilst we've seen how these pieces factor into gaining credibility, and ultimately earning customers' trust if successful, it is more difficult to discern from Twitter activity if the community believes that companies are acting in their best intentions. Despite this difficulty, examining the number of TOC Twitter followers and of the number of accounts followed by TOCs may suggest a level of trust in TOCs.

544 Examining the follower ratio (number of followers per follow) suggests that followers are not simply following an operator's Twitter account out of courtesy for being followed by the train operator. This suggests that there is genuine interest in the TOC and the context of its tweets.

547 Followers may be following a TOC as it views the Twitter account as a source of reliable

548 information, which forms part of the basic level of trust. The low levels of tweets to TOCs in comparison to the number of followers, as discussed as a form of gaining legitimacy, may also 
represent a not just the legitimacy of their operations, but could indicate that followers trust the messages shared on Twitter by TOCs.

Followers, following, and follower ratios were captured on 12 November 2019. All figures are actual numbers except Followers which is indicated in thousands.

Source: Twitter

\begin{tabular}{|c|c|c|c|}
\hline $\begin{array}{c}\text { Train Operating Company } \\
\text { Twitter Account }\end{array}$ & $\begin{array}{l}\text { TOC Followers } \\
\text { (Thousands) }\end{array}$ & $\begin{array}{l}\text { TOC Following } \\
\text { (Actual) }\end{array}$ & $\begin{array}{c}\text { Followers } \\
\text { Ratio }\end{array}$ \\
\hline & \multicolumn{3}{|c|}{ Train Operating Company Interactions } \\
\hline \multicolumn{4}{|c|}{ Open Access Operators } \\
\hline Grand Central & 14.2 & 155 & 92 \\
\hline Heathrow Express & 17 & 1,869 & 9 \\
\hline Hull Trains & 9.8 & 877 & 11 \\
\hline \multicolumn{4}{|c|}{ Concession Operators } \\
\hline London Overground & 472.3 & 1 & 472,300 \\
\hline Merseyrail & 53.6 & 910 & 59 \\
\hline Transport for London Rail & 77.9 & 1 & 77,900 \\
\hline \multicolumn{4}{|c|}{ Franchise Operator: Single Twitter Accounts } \\
\hline c2c Rail & 82.8 & 221 & 375 \\
\hline Caledonian Sleeper & 15.2 & 433 & 35 \\
\hline Chiltern Railways & 94.5 & 2,197 & 43 \\
\hline CrossCountry & 92.3 & 354 & 261 \\
\hline East Midlands Railway & 67.2 & 99 & 679 \\
\hline Gatwick Express & 67.6 & 766 & 88 \\
\hline Great Northern & 53.3 & 150 & 355 \\
\hline Great Western Railway & 779.4 & 393 & 1,983 \\
\hline London North Eastern Railway & 177.6 & 56 & 3,171 \\
\hline ScotRail & 221.6 & 2,033 & 109 \\
\hline Southeastern & 235.2 & 180 & 1,307 \\
\hline Southern & 193.9 & 1,923 & 101 \\
\hline Stansted Express & 10.1 & 183 & 55 \\
\hline Thameslink & 81.2 & 261 & 311 \\
\hline Transport for Wales Rail & 15.7 & 142 & 111 \\
\hline Virgin Trains & 466 & 7,120 & 65 \\
\hline \multicolumn{4}{|c|}{ Franchise Operator: Multiple Twitter Accounts } \\
\hline Greater Anglia News & 3.7 & 342 & 11 \\
\hline Greater Anglia (Help) & 113.4 & 142 & 799 \\
\hline London Northwestern Railway News & .6 & 137 & 4 \\
\hline London Northwestern Railway (Help) & 18.9 & 303 & 62 \\
\hline Northern News & 2.8 & 374 & 7 \\
\hline Northern (Help) & 111.8 & 5,567 & 20 \\
\hline TransPennine Express (News) & 58.5 & 1,595 & 37 \\
\hline TransPennine Express (Help) & 21.4 & 268 & 80 \\
\hline South Western Railway (News) & 31.6 & 180 & 176 \\
\hline
\end{tabular}




\begin{tabular}{lccc} 
South Western Railway (Help) & 432.3 & 94 & 4,599 \\
West Midlands Railway News & .7 & 131 & 5 \\
West Midlands Railway (Help) & 23.6 & 297 & 79 \\
\hline
\end{tabular}

560 This article contributes to the existing literature by providing an analysis of Twitter as a means for private TOCs to obtain a SLO. Examining the Twitter accounts, activity, and policies of private TOCs in the U.K. concluded that the SLO's key components of legitimacy, credibility, and trust. The findings indicated that legitimacy and credibility are reflected in the TOC Twitter activities and policies as these are focused on informing, listening to, and responding to customers. Trust is based on legitimacy and credibility; however, it is difficult to determine if trust legitimately earned. Despite this, the lack of challenges by customers and the interactions suggest that TOCs have earned legitimacy and credibility, which may indicate a level of trust in the TOC.

Bregman's (2012) classifications of social media functions was a useful tool in categorising the tweets and retweets. Although literature on social media advances quickly, this study still proves relevant as the Twitter activity still largely falls within these categories. Despite this, an additional Twitter function, customer service, was prevalent in this study. This may reflect the advancement of social media use, with TOCs moving away from simply providing information to engaging customers in a legitimate two-way dialogue. This is particularly important for moving beyond legitimacy into gaining credibility. Bregman's functions along with the "customer service" category discovered in this study offers an updated classification of social media functions that may be useful in future studies.

580 Tweets and Twitter policies provide organisational lessons for TOCs. Having a presence on

581 Twitter can be an important part of stakeholder engagement. The prominence of real-time information and customer services suggests Twitter is positioned to provide these functions for TOCs and their stakeholders. TOCs responding to tweets suggests that operators should be prepared to engage with stakeholders. The results of the functional analysis of tweets reflected the findings of Bregman's (2012) study of public transport agencies' social media functions in the United States and Canada. As the findings were consistent in private, public, and international contexts; this study may be applicable in multiple geographic and institutional 
settings. Future research could be conducted in order to compare U.K. TOC policies in an international context in order to understand how TOCs

591 A potential issue to note that sharing information through real-time updates and public 592 information may create challenging situations. Information shared is often the result of events 593 out of the TOC's control, particularly when infrastructure related. In these instances, it is the 594 TOC's responsibility to communicate these delays to customers despite their lack of ability to 595 remedy these delays. Planning responsibilities are also a challenge for TOCs as these are the responsibility of the government agencies. In these situations, customers may not make the distinction between the responsibility of TOCs and other transport agencies. Further complicating this is social media platforms maintained by these agencies. In some instances, TOCs retweet the relevant authority's tweets, but this does not appear to be standardised across all TOCs. In order to clarify roles, better coordination of the sharing of information on Twitter would be needed.

602

603 Additional research should broaden the understanding of social media use by TOCs. A 604 limitation of this study was the lack of tweets by TOC customers, with only the replies from TOCs available. In order to address this, future research should analyse the customer tweets to better understand the responses given by TOCs. Questions also remain on how TOCs develop social media policies. As such, future research should conduct a qualitative approach to understanding these influences and factors. Interviews with TOC social media staff should be conducted to understand resources allocated to social media and to understand the goals for its use. In this study, only Twitter was examined, yet additional research should explore the

611 similarities and differences between various TOC social media platforms, such as the uses of 612 Twitter versus Facebook. Further qualitative research may provide a deeper understanding of 613 the decisions rail operators are making to manage their communications, giving insight into 614 how they value the use of these platforms, and to understand if social media platforms are being 615 used by franchised rail operators as a means to fulfil their franchise agreements. Examining 616 these additional areas and contexts would assist in creating a broader picture of social media 617 use and development of policies and strategies for customer engagement by private rail 618 operators. 
Abrams, M., 2015. Passenger's guide to franchising. London: Campaign for Better Transport. Available from https://bettertransport.org.uk/sites/default/files/research-files/franchisingguide.pdf (accessed 5 April, 2018).

Bregman, S., 2012. Uses of Social Media in Public Transportation: A synthesis of Transit Practice. Washington, D.C.: The National Academies Press. https://doi.org/10.17226/14666.

c2c, 2019. Social media. c2c. Available from https://www.c2c-online.co.uk/about-c2c/ourpolicies/social-media/ (accessed 9 September, 2019).

Boutilier, R.G. and Zdziarski, M., 2017. Managing stakeholder networks for a social license to build. Construction Management and Economics 35 (8-9), 498-513. https://doi.org/10.1080/01446193.2017.1289229 Brueckner, M. and Eabrasu, M., 2018. Pinning down the social license to operate (SLO): The problem of normative complexity. Resources Policy 59, 217-226. https://doi.org/10.1016/j.resourpol.2018.07.004

Casas, I. and Delmelle, E. C., 2017. Tweeting about public transit - Gleaning public perceptions from a social media microblog. Case Studies on Transport Policy 5 (4), 634642. https://doi.org/10.1016/j.cstp.2017.08.004.

638 Clegg, B., Orme, R., Owen, C., and Albores, P., 2018. Analysis of a train-operating company's customer service system during disruptions: Conceptual requirements for gamifying frontline staff development. Journal of Rail Transport Planning and Management 8 (1), 56-77. https://doi.org/10.1016/j.jrtpm.2017.12.002.

Collins, C., Hasan, S., and Ukkusuri, S. V., 2013. A Novel Transit Rider Satisfaction Metric: Rider Sentiments Measured from Online Social Media Data. Journal of Public Transportation 16 (2), 21-45. http://doi.org/10.5038/2375-0901.16.2.2.

Cross Country, 2019. Social media policy. Cross Country. Available from https://www.crosscountrytrains.co.uk/about-us/social-media-policy (accessed 9 September, 2019).

650 Efthymiou, D. and Antoniou, C., 2012. Use of social media for transport data collection.

651 Procedia - Social and Behavioral Sciences 48, 775-785. 

Media Usage on Transport Policy: Issues, Challenges, and Recommendations. Procedia Social and Behavioral Sciences 111, 937-946. https://doi.org/10.1016/j.sbspro.2014.01.128.

Gault, P., Cottrill, D. C., Corsar, D., Edwards, P., Nelson, J. D., Markovic, M., Mehdi, M., and Sripada, S., 2019. TravelBot: Utilising social media dialogue to provide journey disruption alerts. Transportation Research Interdisciplinary Perspectives 3 (100062). https://doi.org/10.1016/j.trip.2019.100062.

Grant-Muller, S. M., Gal-Tzur, A., Minkov, E., Nocera, S., Kuflik, T., and Shoor, I., 2015. Enhancing transport data collection through social media sources: methods, challenges, and opportunities for textual data. The Institution of Engineering and Technology Intelligent Transport Systems 9 (4), 407-417. https://doi.org/10.1049/iet-its.2013.0214.

Grand Central, 2018. Social media policy. Grand Central. Available from https://www.grandcentralrail.com/about-us/social-media-policy (accessed 9 September,

Greater Anglia, 2019. Social media. Greater Anglia. Available from https://www.greateranglia.co.uk/contact-us/social-media (accessed 9 September, 2019).

Great Northern, 2019. Social media. Great Northern. Available from

673 Gunningham, N., Kagan, R.A., and Thornton, D., 2004. Social license and environmental https://www.greatnorthernrail.com/help-and-support/contact-us/social-media (accessed 9 protection: Why businesses go beyond compliance. Law \& Social Inquiry 29 (2), 307-41. https://doi.org/10.1111/j.1747-4469.2004.tb00338.x

Hull Trains, 2016. Social media policy. Hull Trains. Available from http://www.hulltrains.co.uk/media/social_media_policy.pdf (accessed 9 September, 2019).

Joyce, S. and Thomson, I., 2000. Earning a social licence to operate: Social acceptability and 681 resource development in Latin America. The Canadian Mining and Metallurgical Bulletin 93 (1037), 49-53.

Kietzmann, J. H., Hermkens, K., McCarthy, I. P., Silvestre, B. S., 2011. Social media? Get serious! Understanding the functional building blocks of social media. Business Horizons 54 (3), 241-251. https://doi.org/10.1016/j.bushor.2011.01.005. 
687

688

689

690

691

692

693

694

695

696

697

698

699

700

701

702

703

704

705

706

707

708

709

710

711

712

713

714

715

716

717

718

The potential and challenges. Transportation Research Part C 77 (April), 275-291. https://doi.org/10.1016/j.trc.2017.02.003.

London Northwestern Railway, 2019. Contact us. London Northwestern Railway. Available from https://www.londonnorthwesternrailway.co.uk/contact-us (accessed 9 September, 2019).

Majumdar, S., 2017. The case of public involvement in transportation planning using social media. Case Studies on Transport Policy 5 (1), 121-133. https://doi.org/10.1016/j.cstp.2016.11.002.

Manetti, G., Bellucci, M., and Bagnoli, L., 2016. Stakeholder Engagement and Public Information Through Social Media: A Study of Canadian and American Public Transportation Agencies. American Review of Public Administration 47 (8), 991-1009. https://doi.org/10.1177/0275074016649260.

Meijer, A. and Thaens, M., 2010. Alignment 2.0: Strategic use of new internet technologies in government. Government Information Quarterly 27 (2), 113-121. https://doi.org/10.1016/j.giq.2009.12.001.

Mellon, J. and Prosser, C., 2017. Twitter and Facebook are not representative of the general population: Political attitudes and demographics of British social media users. Research and Politics, 4 (3), 1-9. https://doi.org/10.1177/2053168017720008.

Merseyrail, 2019. Social media policy. Merseyrail. Available from https://www.merseyrail.org/social-media-policy.aspx (accessed 9 September, 2019).

Murthy, D. (2017) The ontology of tweets: Mixed-method approaches to the study of Twitter. In: Sloan, L. and Quan-Haase, A. (eds.) The SAGE handbook of social media research methods. London: SAGE Publications, 559-572.

Nisar, T. and Prabhakar, G., 2018. Trains and Twitter: Firm generated content, consumer relationship management and message framing. Transportation Research Part A 113 (July), 318-334. https://doi.org/10.1016/j.tra.2018.04.026.

Northern, 2019. Social media. Northern. Available from https://www.northernrailway.co.uk/corporate/social-media (accessed 9 September, 2019). Passenger Focus, 2012. Short and tweet: How passengers want social media during disruption. London: Passenger Focus. Available from https://www.transportfocus.org.uk/ research-publications/publications/short-and-tweet-how-passengers-want-social-mediaduring-disruption (accessed 15 January, 2018). 
Pender, B., Currie, G., Delbosc, A., and Shiwakoti, N., 2014. Social media use during unplanned transit network disruptions: A review of literature. Transport Reviews 34 (4) 501-521. https://doi.org/10.1080/01441647.2014.915442.

Rashidi, T. H., Abbasi, A., Maghrebi, M., Hasan, S., and Waller, T. S., 2017. Exploring the capacity of social media data for modelling travel behaviour: Opportunities and challenges. Transportation Research Part C 77 (February), 197-211. https://doi.org/10.1016/j.trc.2016.12.008.

Schweitzer, L., 2014. A case study for public transit and stigma on Twitter. Journal of the American Planning Association 80 (3), 218-238. https://doi.org/10.1080/01944363.2014.980439.

ScotRail, 2019. Contact us. ScotRail. Available from https://www.scotrail.co.uk/aboutscotrail//contact-us (accessed 9 September, 2019).

Slotterback, C. S., 2011. Planners' perspectives on using technology in participatory process. Environmental and Planning B: Urban Analytics and City Science 38 (3), 468-485. https://doi.org/10.1068/b36138.

Southeastern, 2019. Social rules of engagement. Southeastern. Available from https://www.southeasternrailway.co.uk/about-us/our-policies/social-rules-of-engagement (accessed 9 September, 2019).

Southern Railway, 2019. Twitter. Southern Railway. Available from https://www.southernrailway.com/help-and-support/contact-us/twitter (accessed 9 September, 2019).

South Western Railway, 2019. Social media house rules. South Western Railway. Available from https://www.southwesternrailway.com/contact-and-help/social-media-house-rules (accessed 9 September, 2019).

Thameslink, 2019. Social media. Thameslink. Available from https://www.thameslinkrailway.com/help-and-support/contact-us/social-media (accessed 9 September, 2019).

Thomson, I., and Boutilier, R., 2011. The social license to operate. In: P. Darling (ed.) SME mining engineering handbook. 3rd ed., Colorado, CO: Society for Mining, Metallurgy, and Exploration, 673-90.

TransPennine Express, 2019. Social media policy. TransPennine Express. Available from https://www.tpeexpress.co.uk/help/contact-us/social-media-policy (accessed 9 September, 2019). 
752 Transport for London, 2019. Social media. Transport for London. Available from

753 https://tfl.gov.uk/corporate/terms-and-conditions/social-media (accessed 9 September, 754 2019).

755 Transport for Wales Rail, 2019. Social media policy. Transport for Wales Rail. Available 756 from https://tfwrail.wales/social-media-policy (accessed 9 September, 2019).

757 Warhurst, A., 2001. Corporate citizenship and corporate social investment: Drivers of tri758 sector partnerships. Journal of Corporate Citizenship 1, 57-73. https://doi.org/10.9774/GLEAF.4700.2001.sp.00008

760 West Midlands Railway, 2019. Contact us. West Midlands Railway. Available from 761 https://www.westmidlandsrailway.co.uk/contact-us (accessed 9 September, 2019). 